Investigations

\title{
Freeze Drying of Grape Raw Materials in Red Winemaking
}

\author{
${ }^{1}$ Gennadiy Vyacheslavovich Semenov, ${ }^{2}$ Gennadiy Ivanovich Kasyanov, \\ ${ }^{3}$ Ivan Ivanovich Petkov and ${ }^{4}$ Irina Stanislavovna Krasnova \\ ${ }^{1,4}$ Moscow State University of Food Production, Russia, 109316, Moscow, Talalikhina Street, 33, Russia \\ ${ }^{2}$ Kuban State Technological University, Russia, 350072, Krasnodar, Moscovskaya Street, 2., Russia \\ ${ }^{3}$ JSC Esborn, Department of Freeze Drying, Russia, 101000, Moscow, Malii Zlatoustinskii Street, 6., Russia
}

\author{
Article history \\ Received: 04-07-2017 \\ Revised: 20-07-2017 \\ Accepted: 03-08-2017 \\ Corresponding Author: \\ Gennadiy Vyacheslavovich \\ Semenov \\ Moscow State University of \\ Food Production, Russia, \\ 109316, Moscow, Talalikhina \\ Street, 33, Russia \\ E-mail: sgv47@yandex.ru
}

\begin{abstract}
The aim of this research was the development of technology, which is based on the winemaking from freeze dried grape raw materials. Results of research on the drying of Cabernet Sauvignon grapes were shown. The regimes of preparation of grape raw materials and its subsequent freeze-drying are offered, providing the possibility of successful use in the dried state in the technologies of winemaking. The main feature is the use as a raw material of whole grape berries with skin. The physicochemical analyses, the content of phenolic compounds and sensorial analyses of wine produced by traditional technology, and wine produced from freeze-dried grape raw materials were done. Their comparative evaluation was carried out. It is shown that freeze drying provides a high level of preservation of properties both in raw materials and in the red wine. The sensorial analyses showed that the wine produced by the proposed technology had a more intensive colour and had a slightly more pronounced taste of sweetness and acidity compared to traditional wine. The advantage of this technology is the ability to transport the freeze-dried grape raw materials to any point close to the consumer and to make wine there.
\end{abstract}

Keywords: Vacuum Freeze Drying, Grape Raw Materials, Wine, Physicochemical Analyses, Phenolic Compounds, Sensorial Analyses

\section{Introduction}

The cultivation of grapes is at least 6,000 years old. Back in Ancient Greece, the technologies of viticulture and winemaking were widely developed, then the grapes began to grow in all regions of the Mediterranean, as well as in the regions of the Transcaucasia. Grapes are an excellent raw material for winemaking, because of grapes contains sugars and acids in optimal quantities.

The culture and scale of the use of high-quality wines from grape raw materials has a stable tendency to develop, both in foreign countries and in Russia (Jacobson, 2006). Numerous researches of the nutrition of centenarians in the southern regions have proved that 50-100 grams of dry wine per day favorably affect the body, as they are the source of a wide range of vitamins, minerals and antioxidants (Antonini et al., 2005; Stavridou et al., 2016; Johnson et al., 2006).

Bioactive compounds and vitamins, which are part of the grape raw material, are unstable during storage
(Baraboy, 2009; Sen and Kesgin, 2014; Crisosto and Mitchell, 2002). As a result, grape must be processed within a relatively short time after harvest. For this reason, traditionally the winemaking is tied to the places of growing grapes. Therefore, there is a situation in which specific brands of wines can be produced only in a strictly defined place. This situation leads to an inevitable increase in the prices of finished wines from the customers, it connects with the costs of transportation, storage, customs clearance. However, the development of modern technologies for the preservation of food raw materials through vacuum freeze-drying allows radically changing this centuries-old tradition and produce wine, for example, in the North of Russia or in Finland from grapes grown in sunny Australia. Another advantage of this technology is the possibility of winemaking without being bound to the time of year.

The aim of our research was to develop a vacuum freeze-drying technology of grape raw materials, to make wine from this raw material and to compare its quality with the traditional winemaking. 


\section{Materials and Methods}

\section{Materials}

Raw materials were grapes of European red variety Cabernet Sauvignon, grown in the region of the Krasnodar Territory (Russia) in September 2015.

The grapes were separated from the stems, crushed together with berry skin, and the seeds were removed. Grapes raw material was put on trays by layers; thickness $10 \pm 2 \mathrm{~mm}$ and then the trays were moved to freezing.

\section{Freezing}

Grapes raw material was frozen at $-25^{\circ} \mathrm{C}$ under conditions of forced convection $(5-7 \mathrm{~m} / \mathrm{s})$ in a freezer for 5-7 h. It has been experimentally established that this period was sufficient to freeze most of the moisture in the raw material. The frozen product in the trays is presented in Fig. 1.

\section{Vacuum Freeze-Drying}

For vacuum freeze-drying, trays with frozen grape were placed in a lab scale freeze dryer SVP- 0.36 (Fig. 2 ), the design of it is described in (Semenov, 2013).

The choice of the parameters of vacuum freeze drying grape was carried out as follows. It is known that a high level of quality of thermo labile materials during freeze drying is achieved when $80-85 \%$ of moisture is removed by phase converting ice-to-vapour (Popovski et al., 1975; Clark, 2009).

Numerical values of the quantity of frozen moisture $(\omega$, $\%)$ [omega] in the research samples at different freezing temperatures $\left(t_{f},{ }^{\circ} \mathrm{C}\right)$ was calculated using the formula:

$\omega=\left(1-t_{c r} / t_{f}\right) \times 100 \%$

The cryoscopic temperature $\left(t_{c r}\right)$ was determined experimentally and its value for the research red grapes was $\min 1.5-2^{\circ} \mathrm{C}$. The obtained value corresponds to the data of other researchers (Alegria et al., 2014).

In accordance with the results of calculations from formula (1) in the experiments on vacuum freeze drying, primary drying was carried out at a temperature of min $30-35^{\circ} \mathrm{C}$. At the secondary drying the temperature was always the same, equal to $38-40^{\circ} \mathrm{C}$. The total duration of the drying cycle was $12-14 \mathrm{~h}$. The final moisture content of the freeze-dried grape was $1.5-1.8 \%$.

\section{Winemaking}

The winemaking of red wine from the freeze-dried material included rehydration of the freeze-dried powder from the grape pulp. Then sulphur dioxide was added to the grapes to prevent oxidation and inhibit microbial activity. Enzymes also were added to break down the cell walls. The grape pulp was inoculated with yeast, to carry out the fermentation reaction with maceration. Then the prepared solution was pressing. After pressing the juice was allowed to stand to separate the solids. Then sulphur dioxide was also added to the grapes to prevent oxidation and inhibit microbial activity. Then, the process involved fermentation, formation of wine, and its stabilization.

The freeze drying grape powder was rehydrated with water in a ratio of $1: 3$ (1 kg of dry grape powder per 3 litres of water) to a sugar content of $20 \pm 2 \mathrm{~g} \mathrm{~L}^{-1}$. The product with water was mixed for acceleration the process of a rehydration. The selected level of the ratio of grape powder and water was successfully used in experimental winemaking in volume of 50 litres.

Then sulphur dioxide was added to the prepared solution in an amount of $75 \mathrm{~mL}$ per litre. At the same stage, $4 \mathrm{~g}$ of dry enzyme pectinase per 100 litres was added.

The grape pulp was inoculated with yeast $25 \mathrm{~g}$ per 100 litres. The fermentation with maceration was carried out during for 5 days at a temperature of $25-32^{\circ} \mathrm{C}$ with slow mixing. Then, the pulp was separated from the solution by pressing and squeezing.

The sulphating was carried out in a ratio of $20 \mathrm{mg}$ of sulphur oxide per 1 litre. Further fermentation was carried out at $22^{\circ} \mathrm{C}$ for about 7 days. The final formation of wine took place for about 30 days, and then the wine was stabilized, after the wine was bottled. The bottles were stopped with cork and stored at $16^{\circ} \mathrm{C}$ until analysis.

\section{Physicochemical Analyses of Wine:}

\section{Alcohol Content}

Ethanol production during fermentation was monitored through the measurement of specific gravity and corresponding potential alcohol content extrapolated from the relation.

$\%$ Potential alcohol by volume $=1000 \times($ Starting specific gravity-Final specific gravity) $\div 7.36$ (Duncan and Acton, 1967).

The actual alcohol content of the finished wine and vinegar was measured by distillation (AOAC, 2007). The test sample $(100 \mathrm{~mL})$ was diluted with $50 \mathrm{~mL}$ of distilled water and the solution was neutralized with 1 $\mathrm{M} \mathrm{NaOH}$ solution. The sample was then distilled at $100^{\circ} \mathrm{C}$ until $100 \mathrm{~mL}$ of distillate was obtained. The percentage alcohol by volume was measured using an alcohol hydrometer.

\section{Sugars}

Sugars were measured by Refractometer (RL3).

\section{Acidity (Titratable)}

Acidity (Titratable) was measured using Titrimetric Method of AOAC (2007) (Method 962.12). 


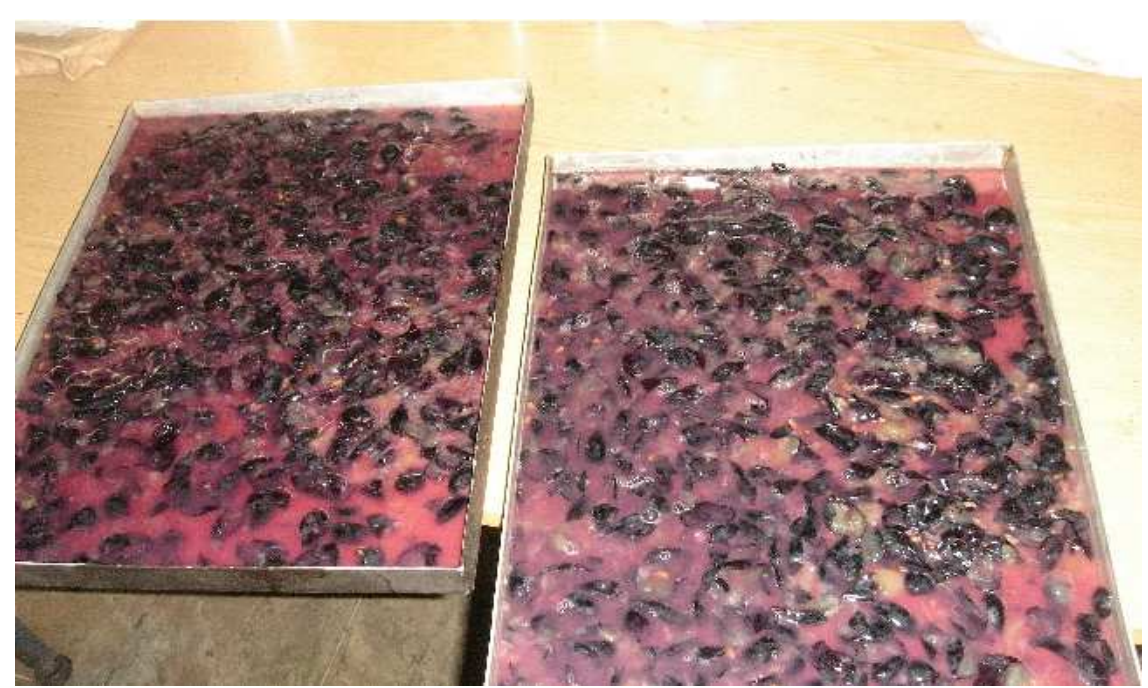

Fig. 1. Cabernet sauvignon grape variety, crushed with skin and frozen for freeze-drying

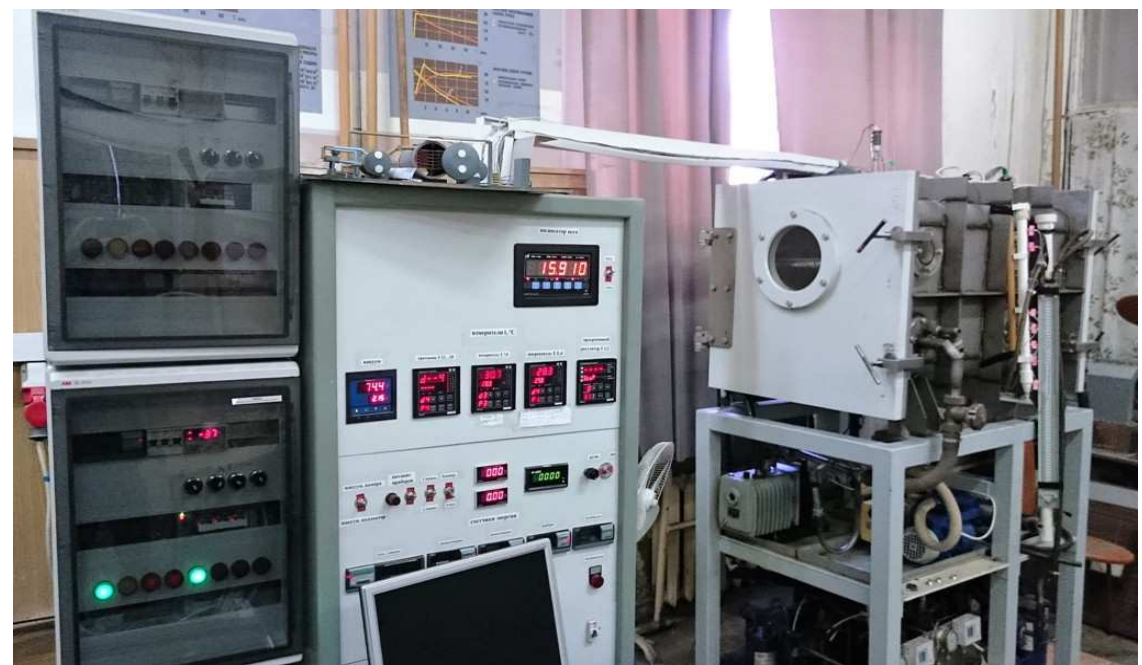

Fig. 2. Head view of the lab scale freeze dryer SVP- 0.36

\section{Acidity (Total Volatile)}

Acidity (Total Volatile) of wine was measured using Titrimetric Method of AOAC (2007) (Method 964.08).

\section{Extract}

Extract of Wine was measured using Pycnometer Method of AOAC (2007) (Method 920.62).

\section{Specific Gravity}

Specific Gravity was measured by Pycnometer Method of AOAC (2007) (Method 920.56).

\section{Active Acidity ( $p H$ ) Determination}

Active acidity $(\mathrm{pH})$ was measured using $\mathrm{pH}-$ meter (Mettler Toledo AG). (Method 960.19 of AOAC) (AOAC, 2007).

\section{Analysis of Organic Acids}

Analysis of Organic Acids was measured by Capillary Electrophoresis with Direct UV Detection (Castiñeira et al., 2002; Mato et al., 2007).

\section{Analysis of Phenolic Compounds:}

Analysis of phenolic compounds in wine was measured by Capillary Electrophoresis with Direct UV Detection (Peres et al., 2009; Sáenz-López et al., 2003).

\section{Sensorial Analyses}

Sensory analyses of wine were determined using with a panel of 9 panelists $(5$ males and 4 females from Moscow State University of Food Production). The panel was requested the participation of healthy adult volunteers (from 18 to 55) who were consumers of red wine and did not have allergies concerning the consumption of wine. 
Cabernet Sauvignon produced by the traditional technology was used as standards. The sensorial analysis included colour intensity (Colour); total aroma intensity (Aroma), extract, acidity, sweetness, astringency. Panelists evaluated each attribute using a ten-point scale to compare red wine produced by the proposed technology with red wine produced by the traditional technology and analyzed as described above (Antoce et al., 2008; Antoce and Namolosanu, 2010; Jackson, 2009). Then, panelists evaluated overall acceptability of the proposed wine.

\section{Statistical Analysis}

The results are presented as the values \pm Standard Deviation (SD). Tukey's test $(\mathrm{p}<0.05)$ (Bower, 2009) was used to detect significant differences between treatments. Pvalues below 0.05 were considered significant.

\section{Results}

\section{Vacuum Freeze Drying}

The freeze-dried grape raw material was a porous layer. It was easily breakable and converted into small particles. The resulting fine particles were less hygroscopic than the freeze-dried pure grape pulp without skin.

\section{Physicochemical Analyses of Wine}

Table 1 presents the values of physicochemical parameters of the wine produced using the proposed technology: $\mathrm{pH}$, alcohol content, content of sugars, titratable acids content, volatile acids content, extract, specific gravity, organic acids content in the finished wine.

\section{Phenolic Compounds}

Table 2 shows the content of phenolic components in wines made using traditional and proposed technology anthocyanins, catechins, leucoanthocyanins, tannins (polyphenols), flavonols and flavones. These biologically active substances first of all form the intensity of the colour of the finished wine and its taste.

\section{Sensorial Analyses}

Sensorial analyses of traditional wine and the wine from freeze-dried grape raw materials are shown in Fig. 3.

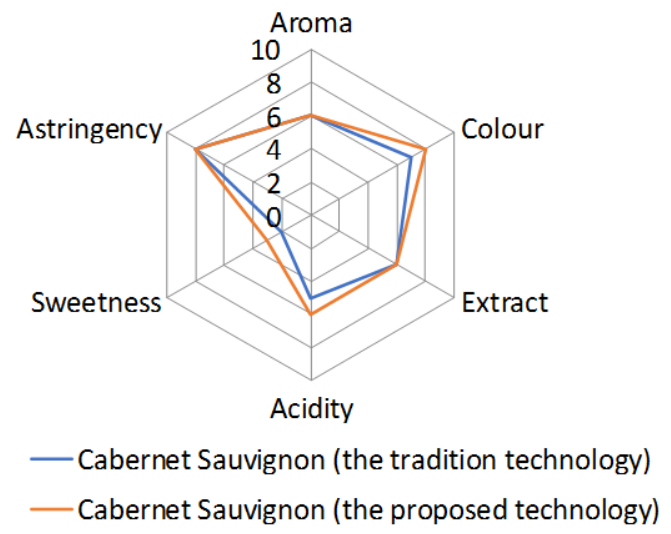

Fig. 3. Sensory profile of the research wine

Table 1. Physicochemical parameters of the researched wine from freeze-dried grape raw materials

\begin{tabular}{lll}
\hline Physicochemical analyses & Standard & Values \\
\hline pH & $3.0-4.2$ & $3.5+0.1$ \\
Ethanol (\% vol.) & $>9$ & $10.97 \pm 0.06$ \\
Sugar, g/l & $<4.0$ & $5.4 \pm 0.2$ \\
Acidity (Titratable), g/l & $>4.0$ & $6.4 \pm 0.1$ \\
Volatile acidity, g/l & $<1.2$ & $0.52 \pm 0.08$ \\
Total Extract, g/l & $>18.0$ & $27.9 \pm 0.3$ \\
Specific Gravity, d & & $0.9993 \pm 0.0002$ \\
Content of organic acids in wine: & $1.5-5.0$ & $2.29+0.14$ \\
Tartaric acid, g/l & $<5.0$ & $1.61+0.32$ \\
Malic acid, g/l & $0.5-2.5$ & $0.51+0.06$ \\
Lactic acid, g/l & $0.25-1.0$ & 1.33 \\
Succinic acid, g/l & & \\
The ratio of organic acids: & & 2.12 \\
(Lactic acid + Malic acid) & & 1.08 \\
Tartaric acid/(Lactic acid + Malic acid) & & 1.4 \\
Tartaric Acid/Malic Acid & & \\
\hline
\end{tabular}

Table 2. Phenolic compounds of the researched wine from freeze-dried grape raw materials

\begin{tabular}{llr}
\hline Phenolic compounds (mg/l) & Traditional technology & Proposed technology \\
\hline Anthocyanins & $350-500$ & 410 \\
Catechins & $380-500$ & 450 \\
Leucoanthocyanins & $90-180$ & 140 \\
Tannins (polyphenols) & $600-4800$ & 2840 \\
Flavonols & $30-40$ & 37 \\
Flavones & $2-8$ & 7 \\
\hline
\end{tabular}




\section{Discussion}

\section{Physicochemical Analyses of Wine}

\section{Active Acidity}

Active acidity is required to confirm the quality and identification of many foods. The $\mathrm{pH}$ forms the taste and the shelf life of the finished wine, and $\mathrm{pH}$ is correlated with the other properties. Freezing and freeze drying by their physical nature are processes that do not lead to a change in $\mathrm{pH}$ values in the dried raw materials.

\section{Alcohol Content}

The results of the researches showed that the alcohol content was at the level of $11 \%$ by volume, and the titratable acidity was $6.4 \mathrm{~g} / \mathrm{dm}^{3}$, which indicates the completion of malic-lactic fermentation. In the process of fermentation of rehydrated freeze-dried grape raw materials the alcohol content corresponding to the generally accepted values for dry red wines is obtained. The alcohol content also characterizes the preservation of sugars during freeze drying, which have a major effect on the fermentation process and its result.

\section{Volatile Acids}

Volatile acids of wine are by-products of alcoholic fermentation. Volatile acids form its characteristic aroma, which is an important property of the quality of wine. Volatile acids are not stable compounds and their concentration can be significantly reduced with the wrong technology of winemaking. However, the proposed vacuum freeze drying regimes provide a high level of preservation of these acids. The volatile acid content obtained in the research Table 1 corresponds to the values recommended by the leading experts in winemaking. (Ferreira et al., 2000; Oliveira et al., 2004; Vilanova et al., 2006; 2007).

\section{Total Extract}

Total extract is considered one of the important quality indicators, allowing assessing the taste of wine. Many components of extractive substances are consumed by yeast and precipitate due to a decrease in solubility in the alcoholcontaining solution. The amount of extractive substances can be reduced by filtration, heating and ageing of wine. The content of the extract depends on the variety of grapes, soil-climatic and meteorological conditions, the degree of maturity of the berries, the way they are processed, and also the type of wine (Chemisova et al., 2014; Comfort, 2008). In our research the total extract content corresponded to the traditional values in the practice of winemaking. This is also evidence that vacuum freeze drying technology ensures the preservation of raw materials.

\section{Specific Gravity}

It is known, the specific gravity of grape juice is more than 1 . During fermentation, the specific gravity of wine decreases. Specific Gravity at level 1 is a sign of wine readiness. These values were obtained in our research, which indicates the readiness of the wine.

\section{Organic Acids}

Organic acids play an important role in the formation of sensorial characteristics of wine. They determine one of the most important indicators of wine tastecharacteristic for this type of active and titratable acidity.

The results show that the winemaking from the freeze-dried grape raw materials does not lead to a decrease in the level of acids in it compared with the use of traditional raw materials from fresh grapes. This is due to the fact that the vacuum freeze drying was carried out without contact of the material with oxygen, and prevented a change in the physicochemical parameters of the raw materials.

The amount of lactic and malic acids and the ratio of tartaric acid to the amount of lactic and malic acids are indicators that are used to identify the authenticity of the wine. Also important is the ratio of the two main acids tartaric and malic, and, the ratio influences on the taste of wine according to Rodopulo (1983). Wine with a better taste and bouquet is obtained at a ratio of 1: 1 to 1 : 3 (Rodopulo, 1983). The results of the researches correspond to these parameters characteristic of traditional red wines (Seliverstova et al., 2001)

The results of the research showed that vacuum freeze drying with the use of the calculated regime parameters ensured the level of preservation of the complex of native properties of grape raw materials, allow to produce wines not inferior to traditional wines made from natural grape raw materials. The proposed regime parameters are adapted to the technical capabilities of industrial drying equipment for production of freeze-dried fruits and vegetables.

\section{Phenolic Compounds}

Taste and aroma of fruits and berries, their colouring depends on the content of phenolic compounds. Phenolic compounds play an important role in the metabolism, are of great practical importance (Kravchenko et al., 2013; López-Vélez et al., 2003; Lachman et al., 2009; Kanner et al., 1994).

The data presented in Table 2 show the level of preservation of phenolic compounds. Preservation of phenolic compounds is important for the formation of the colour of wine, and for its taste characteristics (astringency and fullness of taste). We took for research some grapes of high quality. In addition, in the proposed technology, a peel of grapes was also the raw material, it is rich in phenolic compounds. Freezing and vacuum freeze drying in the recommended regime parameters ensured the preservation of phenolic compounds both in raw materials and in the finished product. 


\section{Sensorial Analyses}

Dry wine produced by the proposed technology has a gently red colour, a harmonious aroma with spicy tones, and a full, harmonious taste. Panelists noted the pleasant bitterness in the taste of wine, which is usually due to the presence of succinic acid. Also, panelists evaluated the shades of astringency in the taste of wine, characteristic for red wines containing tannins, catechins and leucoanthocyanidins.

The most important characteristic of wine is aroma. According to the aroma, specialists can determine what kind of grape is made of wine. They can understand ages of wine and they can guess where it is from. Variety of grapes and terroir is combination of natural and climatic conditions in which it is cultivated and it is the initial parameters for the formation of wine aroma (Chemisova et al., 2014). According to this significant attribute, panelists noted that both variants of wines are identical.

During the sensorial analyses of the traditional wine, the panelists evaluated its sweetness and characteristic acidity. At the same time, the colour of wine from freeze-dried grape raw materials was more intense then that of traditional red wine. However, these differences are insignificant and do not affect the overall acceptability of the two variants of wines, as they are practically equivalent.

\section{Conclusion}

Our researches showed that grapes of the European red variety Cabernet Sauvignon, assembled in the region of the Krasnodar Territory (Russia), possesses a complex of technological characteristics allowing it used for traditional winemaking and for winemaking from freeze-dried raw grape material for subsequent use throughout the year.

We suggested and tested the regime parameters of preparation, freezing and vacuum freeze-drying of raw grape materials. They preserve the original properties of raw grape materials for the production of wine, comparable in quality with the wine produced by traditional technology.

The important point of this technology is that raw grape materials with grape skin is used for obtaining freeze-dried fine particles, and the rehydration of the freeze-dried particles is carried out by adding water in a ratio of 1: (3-6) to a sugar content of $20 \pm 2 \mathrm{~g} \mathrm{~L}^{-1}$.

Freeze-drying using recommended regime parameters does not influenced significant on physicochemical parameters, preserves phenolic compounds grapes (anthocyanins, catechins, tannins, leucoanthocyanins, flavonols and flavones), maintains sensorial and taste profile obtained with their use wines.

The content of organic acids (tartaric acid, malic acid, lactic acid, succinic acid) also does not change in the dried grape raw materials. This also contributes to the achievement of the taste inherent in high-quality red wines from the grape variety Cabernet Sauvignon.

The proposed technology of winemaking from freeze-dried grape raw materials can be realized in regions where grapes are not grown. This will reduce the transportation costs for the delivery of wine to consumers. Winemaking without being bound to the harvesting time is another advantage of this technology

The authors received a patent for the proposed technology (Semenov et al., 2017).

\section{Funding Information}

This research was financially supported by the Grants of the Ministry of education and science of the Russian Federation (grant \# 15.7579.2017/8.9 and grant \# 15.8772.2017/7.8).

\section{Author's Contributions}

Gennadiy Vyacheslavovich Semenov and Ivan Ivanovich Petkov: Designed the research plan and organized the study.

Gennadiy Ivanovich Kasyanov and Irina Stanislavovna Krasnova: Participated in all experiments, coordinated the data-analysis and contributed to the writing of the manuscript.

\section{Ethics}

This article is original and contains unpublished material. The corresponding author confirms that all of the other authors have read and approved the manuscript and no ethical issues involved.

\section{References}

Alegria, M., M. Jara, A. Cataldo, P. Aguirre and A. Gonzalez et al., 2014. Influence of freezing skin grapes to extract phenolic compounds during red wine maceration. Bio Web Conf., 3: 1-4.

Antoce, A.O. and I.C. Namolosanu, 2010. Method for sensory profile construction for defining and evaluating wine tipicality, Romanian Patent. Official Bull. Indust. Property.

Antoce, A.O., I. Namolosanu and A. Tudorache, 2008. Sensory and composition profile of Dornfelder and Regent Wines obtained in Romania. Proceedings 31th World Congress of Vine and Wine (CVW' 08), Verona, Italy, pp: 1-8.

Antonini, F.M, E. Petruzzi, P. Pinzani, C. Orlando and I. Petruzzi et al., 2005. Effect of diet and red wine consumption on serum Total Antioxidant Capacity (TAC), Dehydroepian Drosterone-Sulphate (DHEAS) and insulin-like growth factor-1 (IGF-1) in Italian centenarians. Arch. Gerontol. Geriatr., 41: 151-157. 
AOAC, 2007. Official Methods of Analysis of the Association of Official Analytical Chemists. 18th Edn., Current Through Revision 2, AOAC International, USA.

Baraboy, V.A., 2009. Phenolic compounds of the vine: Structure, antioxidant activity, application. Biotechnology, 2: 67-75.

Bower, J., 2009. Statistical Methods for food Science. 1st Edn., Wiley-Blackwell, Edinburgh, pp: 320.

Castiñeira, A., R.M. Peña, C. Herrero and S. García-Martín, 2002. Analysis of organic acids in wine by capillary electrophoresis with direct UV detection. J. Food Composition Anal., 3: 319-331.

Chemisova, L.E., G.I. Guguchkina, A.V. Prakh, V.M. Redika and L.P. Troshin, 2014. Analysis of forming of organoleptic characteristics of wine materials from sauvignon blanc grapes grown under AF "south" in temrjuksky area depending on the composition of aromatic substances. Scientific J. Kubsau, 98: 1-15.

Clark, J.P., 2009. Case Studies in Food Engineering: Learning from Experience. 1st Edn., Springer Science and Business Media, Dordrecht, ISBN-10: 1441904204, pp: 224.

Comfort, S.A., 2008. More Wine! Guide to Red Winemaking. 1st Edn., More Flavor! Inc., pp: 74.

Crisosto, C.H. and F.G. Mitchell, 2002. Postharvest Handling Systems: Small Fruits. I. Table grapes. In: Postharvest Technology of Horticulture Crops, Kader, A.A. (Ed.), Agriculture and Natural Resources, Oakland, pp: 357-363.

Duncan, P. and B. Acton, 1967. Progressive wine making.

Ferreira, V., R. López and J.F. Cacho, 2000. Quantitative determination of the odorants of young red wines from different grape varieties. J. Sci. Food Agric., 80: $1659-1667$.

Jackson, R.S., 2009. Wine Tasting: A Professional Handbook. 2nd Edn., Academic Press, Amsterdam, ISBN-10: 0080921094, pp: 519.

Jacobson, J.L., 2006. Introduction to Wine Laboratory Practices and Procedures. 1st Edn., Springer Science and Business Media, New York, ISBN-10: 0387251200, pp: 375.

Johnson, M.A., A. Davey, D.B. Hausman, S. Park and L.W. Poon, 2006. Dietary differences between centenarians residing in communities and in skilled nursing facilities: The Georgia centenarian study. AGE, 4: 333-341.

Kanner, J., E. Frankel, R. Granit, B. German and J.E. Kinsella, 1994. Natural antioxidants in grapes and wines. J. Agric. Food Chem., 42: 64-69.

Kravchenko, R.V., P.P. Radchevsky and A.V. Prakh, 2013. The effect of biodux and avibif growth regulators on the quality of grapes and saperavi wine. Scientific J. Kubsau, 89: 1-16.
Lachman, J., M. Sulc, K. Faitová and V. Pivec, 2009. Major factors influencing antioxidant contents and antioxidant activity in grapes and wines. Int. J. Wine Res., 101: 101-121.

López-Vélez, M., F. Martínez-Martínez and C.D. Valle-Ribes, 2003. The Study of phenolic compounds as natural antioxidants in wine. Crit. Rev. Food Sci. Nutr., 43: 233-244.

Mato, I., S. Suárez-Luque and J.F. Huidobro, 2007. Simple determination of main organic acids in grape juice and wine by using capillary zone electrophoresis with direct UV detection. Food Chem., 1: 104-112.

Oliveira, J.M., I. Araújo, O.M. Pereira, J.S. Maia and A.J. Amaral et al., 2004. Characterization and differentiation of five "Vinhos Verdes" grape varieties on the basis of monoterpenic compounds. Anal. Chim. Acta, 513: 269-275.

Peres, R.G., G.A. Micke, M.F. Tavares and D.B. Rodriguez-Amaya, 2009. Multivariant optimization, validation, and application of capillary electrophoresis for simultaneous determination of polyphenols and phenolic acids in Brazilian wines. J. Sep. Sci., 32: 3822-8.

Popovski, V.G., L.A. Bantysh and N.T. Ivasjuk, 1975. Freeze drying of food products of plant origin. Moscow: Food Industry, pp: 335.

Rodopulo, A.K., 1983. Fundamentals of Biochemistry of Winemaking. 1st Edn., Light and Food Industry, Moscow, pp: 240.

Sáenz-López, R., P. Fernández-Zurbano and M. Tena, 2003. Development and validation of a capillary zone electrophoresis method for the quantitative determination of anthocyanins in wine. J. Chromatogr. A., 990: 247-58.

Seliverstova, I.V, A.A. Ivanov and L.A. Ivanova, 2001. Determination of organic acids in wine by liquid ionexclusion chromatography. Winemaking Viticulture. 4: 9-11.

Semenov, G.V., 2013. Vacuum Freeze Drying. 1st Edn., Delhi Plus, Moscow, pp: 264.

Semenov, G.V., G.I. Kasyanov, I.I. Petkov and I.S. Krasnova, 2017. Method for the production of a wine beverage from the freeze-dried raw materials of grapes. Positive Decision.

Sen, F. and M. Kesgin, 2014. Effect of different covering materials used during the pre-harvest stage on the quality and storage life of 'Sultana Seedless' grapes. Food Sci. Technol., 34: 787-792.

Stavridou, K., E.H. Soufleros, E. Bouloumpasi and V. Dagkli, 2016. The phenolic potential of wines from french grape varieties cabernet sauvignon, merlot and syrah cultivated in the region of thessaloniki (Northern Greece) and its evolution during aging. Food Nutrit. Sci., 7: 122-137. 
Vilanova, M. and C. Sieiro, 2006. Determination of free and bound compounds in Albariño wine. J. Food Comp. Anal., 19: 694-697.
Vilanova, M. and C. Sieiro, 2007. Effect of terroir on the volatiles of Vitis vinifera cv. Albariño. J. Sci. Food Agric., 87: 1252-1256. 